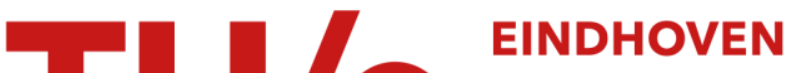 UNIVERSITY OF TECHNOLOGY
}

\section{Regional wall mechanics in the ischemic left ventricle: numerical modeling and dog experiments}

\section{Citation for published version (APA):}

Bovendeerd, P. H. M., Arts, M. G. J., Delhaas, T., Huyghe, J. M. R. J., Campen, van, D. H., \& Reneman, R. S. (1996). Regional wall mechanics in the ischemic left ventricle: numerical modeling and dog experiments. American Journal of Physiology : Heart and Circulatory Physiology, 270(1), H398-H410.

Document status and date:

Published: 01/01/1996

\section{Document Version:}

Publisher's PDF, also known as Version of Record (includes final page, issue and volume numbers)

\section{Please check the document version of this publication:}

- A submitted manuscript is the version of the article upon submission and before peer-review. There can be important differences between the submitted version and the official published version of record. People interested in the research are advised to contact the author for the final version of the publication, or visit the $\mathrm{DOI}$ to the publisher's website.

- The final author version and the galley proof are versions of the publication after peer review.

- The final published version features the final layout of the paper including the volume, issue and page numbers.

Link to publication

\section{General rights}

Copyright and moral rights for the publications made accessible in the public portal are retained by the authors and/or other copyright owners and it is a condition of accessing publications that users recognise and abide by the legal requirements associated with these rights.

- Users may download and print one copy of any publication from the public portal for the purpose of private study or research.

- You may not further distribute the material or use it for any profit-making activity or commercial gain

- You may freely distribute the URL identifying the publication in the public portal.

If the publication is distributed under the terms of Article 25fa of the Dutch Copyright Act, indicated by the "Taverne" license above, please follow below link for the End User Agreement:

www.tue.nl/taverne

Take down policy

If you believe that this document breaches copyright please contact us at:

openaccess@tue.nl

providing details and we will investigate your claim. 


\title{
Regional wall mechanics in the ischemic left ventricle: numerical modeling and dog experiments
}

\author{
P. H. M. BOVENDEERD, T. ARTS, T. DELHAAS, J. M. HUYGHE, \\ D. H. VAN CAMPEN, AND R. S. RENEMAN \\ Department of Mechanical Engineering, Eindhoven University of Technology, 5600 MB Eindhoven; \\ and Departments of Biophysics and Physiology, Cardiovascular Research Institute Maastricht, \\ University of Limburg, 6200 MD Maastricht, The Netherlands
}

Bovendeerd, P. H. M., T. Arts, T. Delhaas, J. M. Huyghe, D. H. van Campen, and R. S. Reneman. Regional wall mechanics in the ischemic left ventricle: numerical modeling and dog experiments. Am. J. Physiol. 270 (Heart Circ. Physiol. 39): H398-H410, 1996.--The mechanics of the ischemic left ventricle during a complete cardiac cycle were simulated using a finite-element model accounting for the thick-walled ventricular geometry, the fibrous nature of the myocardial tissue, and the dependency of active muscle fiber stress on time, strain, and strain rate. Ischemia was modeled by disabling the generation of active stress in a region comprising $\sim 12 \%$ of total wall volume. In the model simulations, the $\sim 12 \%$ reduction in the amount of normally contracting tissue resulted in an $\sim 25 \%$ reduction in stroke work compared with the normal situation. The more-thanproportional loss of stroke work may partly be attributed to storage of elastic energy in the bulging ischemic region. Furthermore the mechanical performance in the nonischemic border zone deteriorated because of reduced systolic fiber stress (if fibers were in series with those in the ischemic region) or reduced fiber shortening (if fibers were parallel). The deformation pattern of the ventricle was asymmetric with respect to the ischemic region because of the anisotropy of the myocardial tissue. Epicardial fiber shortening in and around the ischemic region, as predicted from the model simulations, was in qualitative agreement with shortening, as measured in four dogs in which ischemia was induced by occlusion of the distal part of the left anterior interventricular coronary artery.

finite-element model; ischemic border zone; left ventricular deformation; contractile work

THE PUMP WORK generated by the left ventricle during ejection is the cooperative result of the work generated by the muscle cells in the left ventricular wall. Under normal circumstances, mechanical work generated during the ejection phase, systolic fiber stress and strain, and myocardial perfusion seem to be evenly distributed across the wall (26). A regional decrease in myocardial perfusion, resulting in regional ischemia, induces a redistribution of stress, strain, and work. Insight into the relation between perfusion, stress, strain, and work is important for answering the following questions: Can we determine the location and size of the ischemic region by measuring ventricular deformation? How does the decrease in ventricular performance relate to the decrease in the amount of normally perfused tissue? How is the mechanical performance affected in the border zone of the ischemic region?

Experimentally, local perfusion can be measured using radioactively labeled microspheres (20), but the assessment of local ventricular wall mechanics is difficult. Local deformation can be measured accurately only at a limited number of sites in the left ventricular wall simultaneously $(19,27)$, whereas determination of local work requires additional knowledge of wall stress. Unfortunately, reliable measurement of ventricular wall stress is practically impossible, because insertion of a force transducer damages the tissue (12).

Because of these experimental limitations, mathematical models have been developed to help in understanding the mechanics of the left ventricle. Models for the normal ventricle initially focused mainly on passive behavior $(12,29)$ but, more recently, also included contractile properties dependent on time, strain, and strain rate $(2,3,6,13,17,18)$. Only a few models were presented for the ischemic ventricle $(4,16)$. Bogen et al. (4) used a rotationally symmetric membrane model of the infarcted ventricle, in which infarction was modeled by a change in tissue stiffness, to investigate the relation between ventricular function and infarct size. Perl and Horowitz (16) used a finite-element model to simulate the mechanics of the infarcted left ventricle. They (16) applied an inverse calculation procedure in which active stresses were chosen so that the calculated change in ventricular pressure and volume with time coincided with experimental data. The dependency of active stress on strain and strain rate was neglected.

In the present study, a previously presented finiteelement model $(5,6)$ of the mechanics of the normal left ventricle was extended to investigate the regional mechanics of the ischemic left ventricle. In the model, many aspects of ventricular mechanics are incorporated: the thick-walled geometry; the varying muscle fiber orientation across the wall; the anisotropic nonlinear stress-strain behavior of the passive myocardial tissue; the dependency of active stress on time, strain, and strain rate; the activation sequence of the ventricular wall; and the aortic afterload. Ischemia was simulated by disabling the generation of active stress in part 
of the ventricular wall. Left ventricular geometry, cavity pressure, and distributions of stress and strain in the ventricular wall were calculated from the equilibrium between the forces associated with cavity pressure, wall stress, and kinematic boundary conditions.

With use of the model, the mechanics of the normal and ischemic left ventricle during a complete cardiac cycle were simulated. Comparison of the results of the two simulations reveals the influence of ischemia on left ventricular mechanics. This influence is expressed in terms of global mechanics (stroke work and volume, global ventricular deformation) and local mechanics in and near the ischemic region (fiber stress and strain, generated mechanical work). The deformation, as predicted by the numerical model, was compared with epicardial deformation, as measured in four dog hearts in which an ischemic region was induced by occlusion of a branch of the left anterior interventricular coronary artery. Two additional simulations were performed to investigate the effect of an endo-epicardial gradient in ischemia and of an increase in end-diastolic pressure to simulate full compensation to original stroke volume.

\section{MATERLALS AND METHODS}

\section{Model Describing Left Ventricular Mechanics}

Here we provide a brief description of the model (for more details, see Refs. 5 and 6 , in which the parameter values are identical to those used in this study).

Geometry. In the reference state of the model, defined as the situation with zero transmural pressure, the endocardial and epicardial surfaces are represented by truncated confocal ellipsoids (23), leaving a thick wall between them (Fig. $1 A$ ). The volume of the left ventricular wall $\left(\mathrm{V}_{w}\right)$ was set to $140 \mathrm{ml}$.
On the basis of geometrical data presented by Streeter and Hanna (23), the papillary muscle volume was set to $4 \mathrm{ml}$, the common focal length of the ellipsoids to $43 \mathrm{~mm}$, and the distance between the equatorial plane and the midwall apical point to twice the distance between the equatorial and basal plane. The left ventricular cavity volume $\left(\mathrm{V}_{\mathrm{lv}}\right)$ was set to $40 \mathrm{ml}$ (15). From these data, the outer base-to-apex length $(78 \mathrm{~mm})$ the outer equatorial diameter $(62.6 \mathrm{~mm})$, the base-to-equator distance $(24.8 \mathrm{~mm})$, and the equatorial $(15.0 \mathrm{~mm})$ and apical wall thickness $(7.2 \mathrm{~mm})$ were calculated.

The muscle fibers in the wall were assumed to be parallel to the endocardial and epicardial surfaces. Muscle fiber direction was quantified by the fiber angle $(\alpha ; \mathrm{Fig} .1 A)$, defined as the angle between the fiber direction and the local circumferential direction (22). Within the reported anatomic range (22, 24 ), the transmural distribution of $\alpha$ was chosen (Fig. $1 B$ ) so that, during the ejection phase, active muscle fiber stress is distributed approximately evenly across the ventricular wall (6).

Material properties. In the model, myocardial tissue was assumed to consist of fluid, a connective tissue matrix, and muscle fibers. Each constituent contributes to the total Cauchy stress ( $\boldsymbol{\sigma})$ in the tissue as follows

$$
\boldsymbol{\sigma}=-\mathrm{p} \mathbf{I}=\boldsymbol{\sigma}_{\mathrm{p}}+\sigma_{\mathrm{a}} \mathbf{e}_{\mathrm{f}} \mathbf{e}_{\mathrm{f}}
$$

The fluid, which was assumed to be trapped in the solid. is subject to a hydrostatic pressure - pI, I being the unity tensor. The connective tissue and the muscle fibers, being immersed in the fluid, are subject to the same hydrostatic pressure ( $p$ ). In addition, deformation of the myocardial tissue gives rise to a three-dimensional passive stress $\left(\boldsymbol{\sigma}_{p}\right)$ in the connective tissue and the muscle fibers. The constitutive properties of the passive tissue were chosen so that, in an equibiaxial stretch experiment, the fiber stress $\left(\sigma_{f}\right)$ and the cross-fiber stress $\left(\sigma_{c f}\right)$ increase exponentially with strain, $\sigma_{f}$ being twice as high as $\sigma_{\mathrm{cf}}$ (Fig. $1 C$ ) (30). During systole, the sarcomeres in the muscle fibers generate an additional active
A.

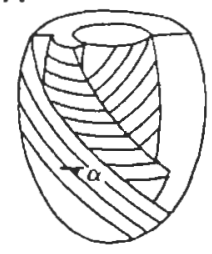

E

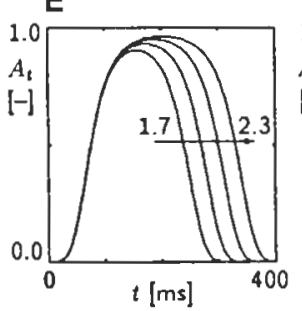

B

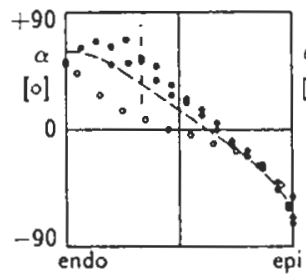

F

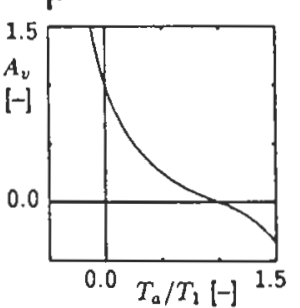

C

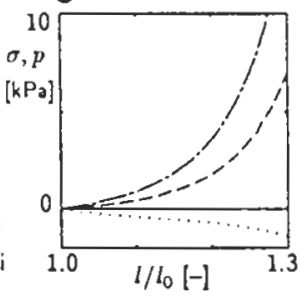

G

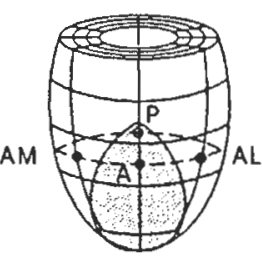

D

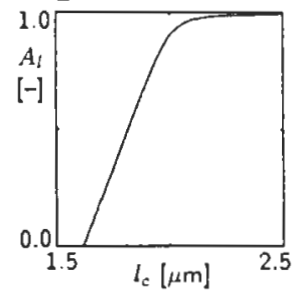

H

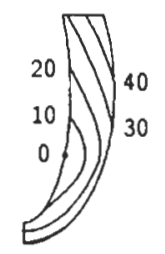

Fig. 1. Characteristics of mathematical model of left ventricular mechanics. $A$ : thick-walled truncated ellipsoid geometry of left ventricle showing fiber angle $(\alpha) . B$ : transmural change in $\alpha$ as assumed in model (dashed line) and measured approximately at equator by Streeter et al. (24)(0) and Streeter (22)( $)$; vertical dashed line, location of trabecula-compacta interface in latter measurements; endo and epi, endo- and epicardial. $C$ : change in passive fiber stress (dot-dashed line), cross-fiber stress (dashed line), and hydrostatic pressure (dotted line) during an equibiaxial stretch experiment as a function of stretch $\left(l / l_{0}\right) . D$ : dependency of active stress on contractile element length $\left(l_{c} ; E q\right.$. 4). $E$ : dependency of active stress on time since activation $(t)$ for sarcomere lengths of $1.7,1.9,2.1$, and $2.3 \mu \mathrm{m}(E q .4)$. $F$ : normalized shortening velocity $\left(A_{l}\right)$ of contractile element as a function of active fiber stress $\left(\mathrm{T}_{\mathrm{a}} / \mathrm{T}_{1} ; E_{q} .5\right) . G$ : location of ischemic region in anterior part of ventricular wall; local mechanics in Fig. 5 are presented at posterior $(P)$, anterior-medial $(A M)$, anterior $(A)$, and anterior-lateral $(A L)$ sites. $H$ : activation sequence of ventricular wall indicated by isochrones at $10-\mathrm{ms}$ intervals. 
stress component $\sigma_{a} \mathbf{e}_{\mathfrak{f}} \mathbf{e}_{\mathfrak{f}}$, parallel to the fiber direction $\left(\mathbf{e}_{\mathrm{f}}\right)$. The contractile behavior is described using a slightly adapted version of the model presented by Arts et al. (2), which was based on Hill's three-element model (10). We utilize the active first Piola-Kirchhoff stress $\left(\mathrm{T}_{\mathrm{a}}\right)$, defined as generated active force $\left(\mathrm{F}_{\mathrm{a}}\right)$ per unit cross-sectional area $\left(A_{0}\right)$ of the sarcomere in the reference situation

$$
\mathrm{T}_{\mathrm{a}}=\frac{\mathrm{F}_{\mathrm{a}}}{A_{0}}=\sigma_{\mathrm{a}} \frac{A}{A_{0}}=\sigma_{\mathrm{a}} \frac{l_{\mathrm{s} .0}}{l_{\mathrm{s}}}
$$

where $A$ represents the actual cross-sectional area of the sarcomere and $l_{\mathrm{s}}$ and $l_{\mathrm{s} .0}$ denote the actual and reference sarcomere length, respectively. The sarcomere was modeled as a contractile element in series with an elastic element. The magnitude of $\mathrm{T}_{\mathrm{a}}$ depends on $l_{\mathrm{s}}$, the length of the contractile element $\left(l_{c}\right)$, and the time $(t)$ elapsed since the moment of activation of the sarcomere

$$
\mathrm{T}_{\mathrm{a}}=f_{\mathrm{T}} \frac{l_{\mathrm{s}}-l_{\mathrm{c}}}{l_{\mathrm{se}}} \mathrm{T}_{\text {nax }}
$$

where

$$
\mathrm{T}_{\text {max }}=\mathrm{T}_{1} A_{l}\left(l_{\mathrm{c}}\right) A_{t}\left(t, l_{\mathrm{s}}\right)
$$

The factor $f_{\mathrm{T}}$ represents the ability of the tissue to generate active stress and varies between 0 (completely ischemic tissue) and 1 (normally contracting tissue). The constant $l_{\text {se }}$ $(0.05 \mu \mathrm{m})$ represents the maximum length of the series elastic element. The constant $\mathrm{T}_{1}(110 \mathrm{kPa})$ determines the level of maximum isometric stress. The length dependency $A_{l}\left(l_{c}\right)$ and time dependency $A_{t}\left(t, l_{s}\right)$ are shown in Fig. $1, D$ and $E$. The time derivative of $l_{c}$ depends on $\mathrm{T}_{\mathrm{a}}$ according to a slightly adapted Hill (10) velocity-stress relation (Fig. $1 F$ )

$$
-\frac{1}{v_{1}} \frac{\mathrm{d} l_{\mathrm{c}}}{\mathrm{d} t}=A_{t} \cdot\left(\frac{\mathrm{T}_{\mathrm{a}}}{\mathrm{T}_{1}}\right)
$$

with asymptote shortening velocity $c_{1}(15 \mu \mathrm{m} / \mathrm{s})$ and asymptote stress $\mathrm{T}_{1}(110 \mathrm{kPa})$. The location of the ischemic region was chosen to represent the ischemic region that results from the occlusion of a branch of the left anterior interventricular coronary artery (Fig. $1 G$ ). The volume of the ischemic region is $-12 \%$ of the total wall volume.

Generation of active stress is induced by electrical depolarization of the cell membrane. The sequence of depolarization of the ventricular wall was assumed to be rotationally symmetric. Depolarization starts in the endocardial apical region and reaches the epicardial basal region after $-50 \mathrm{~ms}$ (Fig. $1 H$ ). The activation pattern was assumed to remain unaffected by ischemia. The aortic hemodynamic load is simulated by an ideal valve, followed by the aortic input impedance, which is simulated by a characteristic resistance in series with a parallel combination of an arterial compliance and peripheral resistance (28).

Calculation procedure. The deformation of the left ventricle during the cardiac cycle was calculated from the equations of conservation of mass and momentum. A Galerkin-type finiteelement method was used to convert these equations to a 20 -node three-dimensional brick-element formulation. Within the element, the displacement field was approximated by quadratic interpolation of the displacements of the 20 nodes. The hydrostatic pressure field was approximated by linear interpolation of the pressures at the eight corner nodes. The ventricular geometry was composed of 108 elements (Fig. $1 G$ ). While a cardiac cycle was simulated, axial motion of all nodes in the basal plane and circumferential motion of the nodes in the endocardial basal ring were suppressed. A uniform pressure $p_{\mathrm{lv}}$ was applied to the endocardial surface, while epicardial load was set to zero.

In the simulation of a cardiac cycle, generally 5-ms time steps were used. At each time increment, a deformed ventricular geometry was calculated in which the forces associated with cavity pressure, wall stress, and the kinematic boundary conditions balanced while wall volume was constant. The simulation started with the diastolic filling phase, during which cavity pressure was prescribed to increase from $0 \mathrm{kPa}$ at $t=0 \mathrm{~ms}$ to $1 \mathrm{kPa}$ at a prescribed $t=150 \mathrm{~ms}$. At $t=150 \mathrm{~ms}$, depolarization was initiated in the endocardial basal region (Fig. $1 H$ ). Active stress was generated immediately after depolarization. The diastolic phase ended with the closure of the mitral valve, which was assumed to occur at $t=200 \mathrm{~ms}$. During the following isovolumic contraction phase, at each time increment, cavity pressure was determined iteratively from the condition that it must balance the active and passive wall stress while cavity volume equals its end-diastolic value. As soon as the cavity pressure exceeded a prescribed aortic pressure level of $10 \mathrm{kPa}$, the ejection phase started. During the ejection phase, at each time increment, cavity pressure was determined iteratively until the aortic flow, which depended on the aortic afterload, matched the rate of decrease of cavity volume. The ejection phase ended as soon as the calculated aortic flow reversed. The isovolumic relaxation phase was simulated analogously to the isovolumic contraction phase. The calculation ended at a prescribed time $t=600$ $\mathrm{ms}$, at which the muscle fibers were completely passive again. No ventricular filling was allowed during the relaxation phase.

The model was implemented in a finite-element package NONSYS (not commercially available). A complete simulation of a cardiac cycle took $\sim 15 \mathrm{~h}$ of computer processing unit time on a Silicon Graphics Challenge L computer in single processor mode.

Presentation of results from the simulations. Simulations were performed for the normal and the ischemic ventricle. Global ventricular mechanics, as calculated in the simulations, were characterized by the change in left ventricular pressure, volume, and geometry and aortic flow as a function of time. In principle, the local mechanical behavior in the ventricular wall must be described by six stress and six strain components. We have restricted ourselves to quantities that are most relevant in view of muscular energetics: $\mathrm{T}_{\mathrm{a}}$ and $l_{\mathrm{s}}$. The mean active stress during the ejection phase $\overline{\mathrm{T}}_{\mathbf{a}}$ was calculated from

$$
\overline{\mathrm{T}}_{\mathrm{a}}=\frac{1}{t_{\mathrm{ee}}-t_{\mathrm{be}}} \int_{t_{\mathrm{be}}}^{t_{\mathrm{ee}}} \mathrm{T}_{\mathrm{a}}(t) \mathrm{d} t
$$

where $t_{\mathrm{be}}$ and $t_{\mathrm{ee}}$ denote the beginning and end of the ejection phase. To compare active stresses at identical sites in the normal (subscript $n$ ) and ischemic (subscript $i$ ) ventricle, we use the normalized active stress $\hat{T}_{a}$, defined as

$$
\hat{\mathrm{T}}_{\mathrm{a}}=\overline{\mathrm{T}}_{\mathrm{a}, \mathrm{i}} / \overline{\mathrm{T}}_{\mathrm{a}, \mathrm{n}}
$$

On the basis of the change in sarcomere length during the ejection phase $\left(\Delta l_{\mathrm{s}, \mathrm{e}}\right)$

$$
\Delta l_{\mathrm{s}, \mathrm{e}}=l_{\mathrm{s}}\left(t_{\mathrm{ee}}\right)-l_{\mathrm{s}}\left(t_{\mathrm{be}}\right)
$$

we define normalized sarcomere shortening $\Delta \hat{l}_{\mathrm{s}, \mathrm{e}}$ as

$$
\Delta \hat{l}_{\mathrm{s}, \mathrm{e}}=\Delta l_{\mathrm{s}, \mathrm{e} . \mathrm{i}} / \Delta l_{\mathrm{s}, \mathrm{e}, \mathrm{n}}
$$


Locally generated external work $(w)$ per unit of tissue volume was calculated from the area of the local fiber stress-stretch loop

$$
w=\oint_{\text {cycle }} \mathrm{T}_{\mathrm{a}} \mathrm{d}\left(\frac{l_{\mathrm{s}}}{l_{\mathrm{s}, 0}}\right)
$$

where $l_{\mathrm{s}, 0}$ was assumed to equal $2.0 \mu \mathrm{m}$. Normalized work $(\hat{w})$ was defined as the ratio of the work generated in the ischemic ventricle $\left(w_{\mathrm{i}}\right)$ to the work generated at the same location in the normal ventricle $\left(w_{n}\right)$

$$
\hat{w}=w_{\mathrm{i}} / w_{\mathrm{m}}
$$

\section{Dog Experiments}

Experiments were performed on four mongrel dogs of either sex and unknown age ranging in weight from 23 to 29 $\mathrm{kg}$. Preparation and measurements were performed as described by Delhaas et al. (8) and are recapitulated briefly below.

Preparation. The animal was premedicated with an intramuscular injection of fluanisone $(10 \mathrm{mg} / \mathrm{kg})$ and fentanyl base $(0.2 \mathrm{mg} / \mathrm{kg})$. Anesthesia was induced with an injection of pentobarbital sodium (10 $\mathrm{mg} / \mathrm{kg})$ and was maintained, after endotracheal intubation, with nitrous oxide $\left(33 \% \mathrm{O}_{2}-67 \%\right.$ $\mathrm{N}_{2} \mathrm{O}$ ) and a continuous infusion of pentobarbital sodium (2 $\left.\mathrm{mg} \cdot \mathrm{kg}^{-1} \cdot \mathrm{h}^{-1}\right)$. When necessary, a sodium bicarbonate solution $(4.2 \%)$ was administered intravenously to adjust the acid-base balance, as determined from arterial blood samples. Ventilation was kept constant with a positive-pressure respirator. The chest was opened, and the heart was suspended in a pericardial cradle. An epicardial bipolar platinum pacing electrode was sutured to the right atrium (Fig. 2).

Measuring techniques. Left ventricular and aortic pressure were measured with catheter-tipped micromanometers (Millar PC-470). Aortic volume flow was measured with an electromagnetic flowmeter (Skalar Transflow 601). Regional myocardial perfusion was measured using radioactively labeled microspheres (19). Two-dimensional epicardial deformation was determined with the use of a video technique (20). Approximately 40 white markers $(1.5 \mathrm{~mm}$ diameter $)$ were
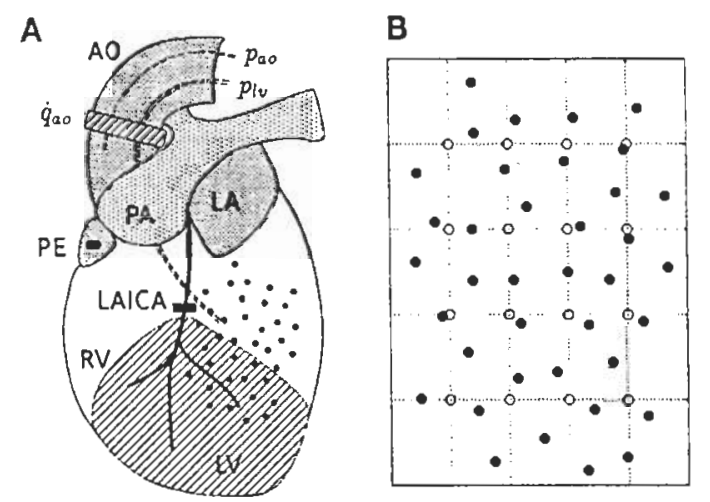

Fig. 2. Experimental setup. A: schematic view of heart showing aorta (AO), pulmonary artery (PA), left atrium (LA), left anterior interventricular coronary artery (LAICA), right ventricle (RV), and left ventricle (LV). Instrumentation includes catheter-tipped manometers for measuring aor tic pressure $\left(p_{a 0}\right)$ and left ventricular pressure $\left(p_{w}\right)$, electromagnetic flow probe for measuring aortic volume flow $\left(q_{a c}\right)$, atrial pacing electrode (PE), occluder (bar) of distal part of LAICA resulting in an ischemic region (shaded area), and markers (-) used for determination of epicardial deformation. $B$ : subdivision of area covered with markers into $5 \times 5$ subregions. Epicardial deformation is determined in 16 overlapping regions, each consisting of 4 adjacent subregions and ascribed to central point (O). attached to the epicardial surface of the left ventricular anterior wall at mutual distances of $\sim 6 \mathrm{~mm}$ (Fig. 2). The area covered with markers extended $3-4 \mathrm{~cm}$ in circumferential and $4-5 \mathrm{~cm}$ in base-to-apex direction. The motion of the markers was recorded on videotape with use of a videocamera with a $200-\mathrm{mm}$ teleobjective positioned at a distance of $2.5 \mathrm{~m}$. To avoid blurring of the image, a video-triggered xenon flashlight illumination was applied.

Protocol. Epicardial fiber direction and base-to-apex direction were determined by visual inspection and recorded on videotape. Atrial pacing was applied so that regular activation was obtained at minimum current and pace levels. After 15 min of pacing, hemodynamics and epicardial deformation were recorded and radioactively labeled microspheres were injected into the left atrium. Subsequently, the distal part of the left anterior interventricular coronary artery was occluded. After $15 \mathrm{~min}$, the measurements were repeated. The experiment was terminated by administration of an overdose of pentobarbital sodium. The heart was excised, the atria and the right ventricle were removed, and $V_{w}$ was determined by weighing, with assumption of a density of $1.05 \mathrm{~g} / \mathrm{ml}$. The epicardial half of the left ventricular wall was dissected into blocks of tissue that weighed $\sim 0.5-1 \mathrm{~g}$.

Data analysis. Hemodynamic data were sampled $(200 \mathrm{~Hz})$ and digitized ( 12 bit). The beginning of the ejection phase was defined as the moment at which left ventricular pressure exceeded end-diastolic aortic pressure. The change in ventricular volume during ejection, the duration of the ejection phase, and stroke volume were determined from the aortic flow signal. To determine epicardial deformation, 64 consecutive video frames $(50 \mathrm{~Hz})$ were digitized. Marker traces were determined using a singular-value decomposition technique (14). The region covered with markers was subdivided into $5 \times 5$ subregions (Fig. $2 B$ ). Local epicardial deformation was determined from the marker traces in 16 overlapping regions, each consisting of $2 \times 2$ subregions. Regional subepicardial blood flow was determined from the radioactivity of the blocks of subepicardial tissue, as measured with a gamma counter (20).

Data presentation. Epicardial deformation was referred to the moment of midejection (subscript me) and quantified in terms of fiber strain $\epsilon_{f}$

$$
\epsilon_{\mathrm{f}}=\left(l_{\mathrm{f}}-l_{\text {f.me }}\right) / l_{\text {f.me }}
$$

where $l_{\mathrm{f}}$ represents epicardial fiber length. Change in cavity volume during ejection was quantified in terms of volume strain $\epsilon_{V}$

$$
\epsilon_{\mathrm{V}}=\left(\mathrm{V}_{\mathrm{k}}-\mathrm{V}_{\mathrm{k}, \mathrm{me}}\right) \mathrm{V}_{\mathrm{w}}
$$

where the difference $V_{\mathrm{k}}-V_{\text {lvme }}$ was calculated by integrating aortic flow in time

$$
\mathrm{V}_{\mathrm{lv}, t}-\mathrm{V}_{\mathrm{lv}, \mathrm{me}}=\int_{t_{\mathrm{bee}}}^{t_{\mathrm{me}}} \mathrm{q}_{\mathrm{ag}}(\tau) \mathrm{d} \tau-\int_{t_{\mathrm{be}}}^{t} \mathrm{q}_{\mathrm{ao}}(\tau) \mathrm{d} \tau
$$

During the ejection phase, $\epsilon_{f}$ was approximately linearly related to $\epsilon_{\mathrm{V}}(8)$. To be able to compare results from different hearts with different stroke volumes, we used the fiber-tovolume strain ratio $(a)$, which was determined from the best linear fit between $\epsilon_{\mathrm{f}}$ and $\epsilon_{\mathrm{V}}$

$$
\epsilon_{\mathrm{f}}=a \epsilon_{\mathrm{V}}
$$

The degree of ischemia could not be defined by the factor $f_{\mathrm{T}}$ that was used in the numerical model. Instead we quantified the degree of ischemia by the normalized local perfusion $(\hat{\mathrm{q}})$, which was obtained by dividing $q$ by perfusion in a nonisch- 
emic subepicardial region $\left(\mathrm{q}_{\mathrm{ni}}\right)$

$$
\hat{\mathrm{q}}=\mathrm{q} / \mathrm{q}_{\mathrm{ni}}
$$

\section{RESULTS}

\section{Results From the Simulations}

Global hemodynamics and deformation. In Fig. 3, ventricular pressure and volume and aortic flow are presented as a function of time. Maximum pressure, ejected volume, and maximum aortic flow were lower in the ischemic ventricle than in the normal ventricle: 18.6 vs. $20.5 \mathrm{kPa}, 27.6$ vs. $33.7 \mathrm{ml}$, and $235 \mathrm{vs} .265 \mathrm{ml} / \mathrm{s}$, respectively. Stroke work, as calculated from the area enclosed by the pressure-volume loop, was reduced from 0.62 to $0.46 \mathrm{~J}$. Thus, as a result of an ischemic region comprising $\sim 12 \%$ of the ventricular wall, stroke volume and stroke work were reduced by $\sim 18 \%$ and $25 \%$, respectively.

In Fig. 4, the shape of longitudinal cross sections of the normal and ischemic ventricle is shown at four moments during the cardiac cycle. In the geometry at the beginning of the simulation, the location of the ischemic region is indicated. At the remaining three moments, the displacement of points in the wall was separated into a radial, an axial, and a circumferential component. For clarity, in Fig. 4, the circumferential displacements are shown in terms of the angle of rotation $\left(\phi_{\text {rot }}\right)$ around the long axis. A positive $\phi_{\text {rot }}$ corresponds to a counterclockwise rotation when the ventricle is viewed from the base.

Deformation of the cross section of the normal ventricle is shown in Fig. 4, top. During the filling phase,
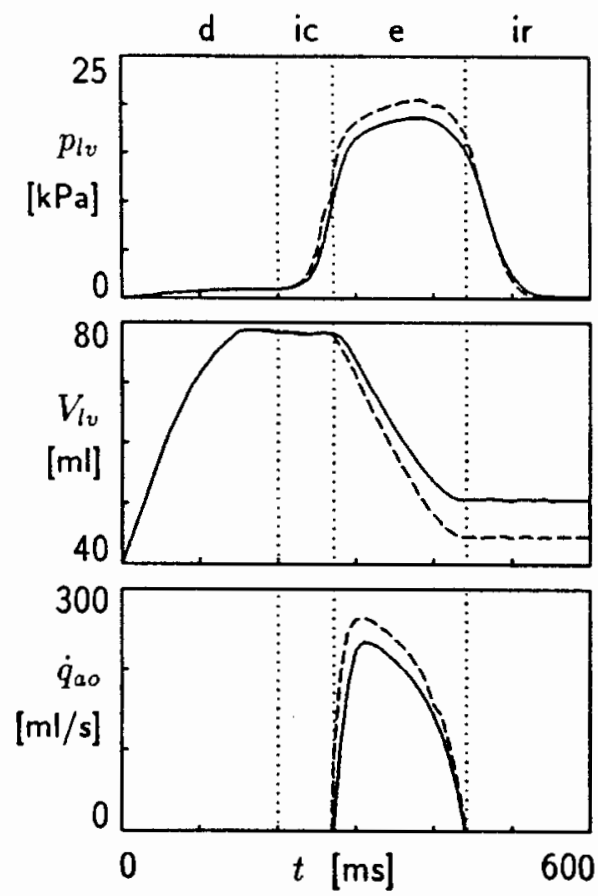

Fig. 3. Change in left ventricular pressure $\left(p_{l v}\right)$, left ventricular volume $\left(\mathrm{V}_{\mathrm{lv}}\right)$, and aortic volume flow $\left(\mathrm{q}_{\mathrm{ao}}\right)$ as a function of time $(t)$, as calculated for ischemic (solid line) and normal (dashed line) ventricle. Vertical dotted lines, transitions among diastolic (d), isovolumic contraction (ic), ejection (e), and isovolumic relaxation (ir) phases. cavity volume increased from 40 to $78 \mathrm{ml}$, ventricular diameter and length increased, wall thickness decreased, and angles of rotation remained $<10^{\circ}$. During the isovolumic contraction phase, the ventricle became more conical, while angles of rotation increased strongly to $>40^{\circ}$. During ejection, cavity volume decreased to 44 $\mathrm{ml}$, mainly due to a reduction in ventricular diameter.

Deformation of the ischemic ventricle is shown for the septal half (Fig. 4, middle) and the anterior half (Fig. 4, bottom). In the model, ischemia was considered an on-off effect; i.e., the myocardial tissue was defined to be ischemic $\left(f_{\mathrm{T}}=0\right)$ or normally contracting $\left(f_{\mathrm{T}}=1\right)$. As can be observed in Fig. 4, the postprocessing procedure involved some spatial averaging of the quantities across the element volume, resulting in a smooth transition zone between the completely ischemic region and the normally contracting region. During diastolic filling, deformation was identical to that in the normal ventricle. During the systolic phase, an outward bulging of the ischemic region occurred. In the ischemic region, the wall was relatively thin. During ejection, the deformation of the anterior wall was asymmetric, despite the symmetric location of the ischemic region with respect to the anterior wall.

Local mechanics. To illustrate local mechanics, we first consider four epicardial points at the same latitude located on the posterior wall (point $P$ in Fig. $1 G$ ), in the ischemic region on the anterior wall (point $A$ ), and medial (toward the septum, point $A M$ ) and lateral (point $A L$ ) of the ischemic region. In the normal ventricle, local mechanics in these points were identical, because we assumed no circumferential variation in geometry or material properties.

In Fig. $5 A, \mathrm{~T}_{\mathrm{a}}$ is plotted vs. $t$ during a complete cardiac cycle. In the normal ventricle, $\mathrm{T}_{\mathrm{a}}$ rose to $\sim 50$ $\mathrm{kPa}$. In the ischemic ventricle, the change in $\mathrm{T}_{\mathrm{a}}$ with $t$ was approximately normal in point $P$, located far from the ischemic region. No active stress was generated within the ischemic region (point $A$ ). Although points $A M$ and $A L$ are located symmetrically with respect to the ischemic region, changes in the level of active stress with respect to the normal situation were opposite: in $A M$ active stress was lower than normal, whereas in $A L$ it was higher.

The change in $l_{\mathrm{s}}$ as a function of $t$ is shown in Fig. $5 B$. In the normal ventricle, during diastole, $l_{\mathrm{s}}$ increased from the reference value of $2.00 \mu \mathrm{m}$ to $\sim 2.15 \mu \mathrm{m}$. Next, $l_{\mathrm{s}}$ decreased to $\sim 2.05 \mu \mathrm{m}$ at the end of the isovolumic contraction phase and to $\sim 1.90 \mu \mathrm{m}$ at the end of the ejection phase. In case of ischemia, in point $P$ the time course of $l_{\mathrm{s}}$ remained virtually the same. In the ischemic region, $l_{\mathrm{s}}$ increased to $\sim 2.40 \mu \mathrm{m}$ during the ejection phase (point $A$ ). In points $A M$ and $A L$, changes in $l_{\mathrm{s}}$ with respect to the normal situation were also opposite: in $A M$ sarcomere shortening during the ejection phase was more than normal, whereas in $A L$ it was less than normal.

In Fig. $5 C, \mathrm{~T}_{\mathrm{a}}$ is plotted vs. fiber stretch ratio $\left(l_{\mathrm{s}} / l_{\mathrm{s}, 0}\right)$. The enclosed area of the stress-stretch loops represents the amount of external work generated per unit of volume per cardiac cycle $(E q .10)$. In the normal 


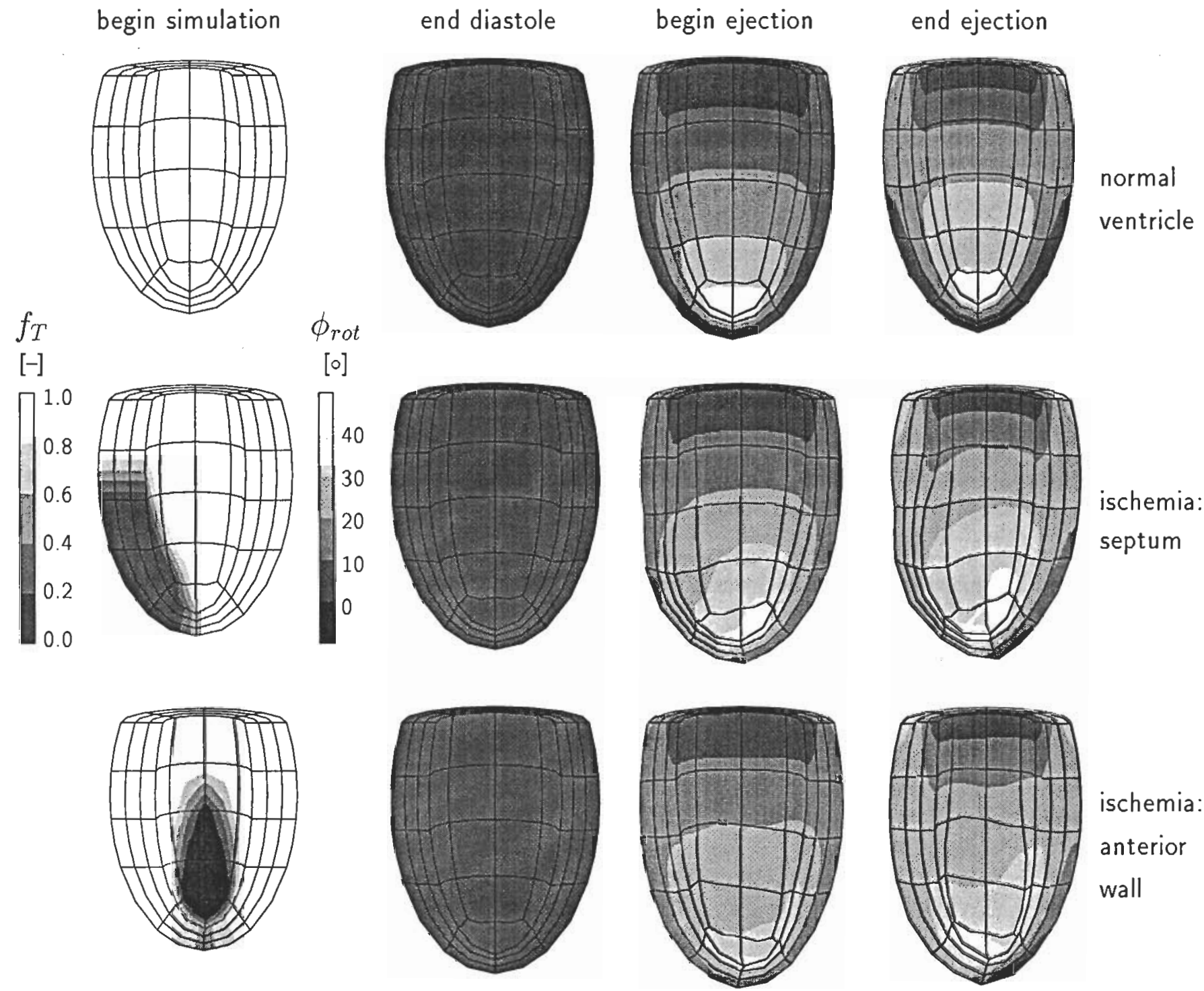

Fig. 4. Change in shape of normal and ischemic ventricle during cardiac cycle. In geometry at beginning of simulation, location of ischemic region is indicated as region with $f_{\mathrm{T}}<1$. At remaining 3 moments, radial and axial displacements are shown directly; whereas circumferential displacements are shown in terms of angle of rotation around long axis $\left(\phi_{\mathrm{rut}}\right)$. Positive $\phi_{\mathrm{rut}}$ corresponds to counterclockwise rotation when ventricle is viewed from base.

ventricle, the stress-stretch loop was approximately rectangular, and generated work equaled $\sim 5 \mathrm{~m} . \mathrm{J} / \mathrm{ml}$. In the ischemic ventricle, in point $P$ the loop remained virtually unchanged. In the ischemic region (point $A$ ), no active stress and work were generated. In the nonischemic border zone of the ischemic region, external work was less than normal, either by a reduced active stress level (point $A M$ ) or by a reduced systolic sarcomere shortening (point $A L$ ).

A more general overview of local mechanics in the normal ventricle is presented in Fig. 6 . Figure $6 A$ shows the pattern of activation of the ventricular wall. Figure $6 B$ shows that the active first Piola-Kirchhoff fiber stress, as averaged over the ejection phase, is distributed quite homogeneously across the ventricular wall, except for the apical region, where stress is relatively low. This homogeneous distribution is the result of the particular choice of the muscle fiber orientation (6). As shown in Fig. 6C, sarcomere shortening during the ejection phase is distributed quite inhomogeneously, ranging from 0.1 to $0.3 \mu \mathrm{m}$. This inhomogeneity is reflected in a rather inhomogeneous distribution of generated mechanical work (Fig. 6D).

Because in this study we regard local mechanics in the ischemic ventricle as a disturbance of that in the normal ventricle, local mechanics in the ischemic ventricle are presented in terms of relative quantities with respect to the normal situation. In Fig. 7, these quantities are presented for the anterior half of the ventricle. At the epicardial surface (Fig. 7, top row), muscle fibers are oriented from the basal-medial (top left) side to the apical-lateral (bottom right) side, whereas at the endocardium (Fig. 7, bottom row) fibers run from the basal-lateral (top right) to the apicalmedial (bottom left) side. In Fig. $7 \mathrm{~A}$, the ischemic region is indicated. 
Fig. Local mechanics in ischemic isolid line and normal (dashed line) ventricle at posterior $(P)$, anterior $(A)$, anterior-medial $(A, C)$, and anterior-lateral $(A L)$ locations, as indicated in Fig. $1 G$. $A$ : active first Piola-Kirchhoff fiber stress $\left(\mathrm{T}_{\mathrm{i}}\right)$ plotted vs. time (t). B: sarcomere length $(l$, plotted vs.t. $C: T_{i}$ plotted vs. fiber stretch $1 / / l_{*}(1)$. Vertical dotted lines in $A$ and $B$. transitions between various phases in cardiac crele.

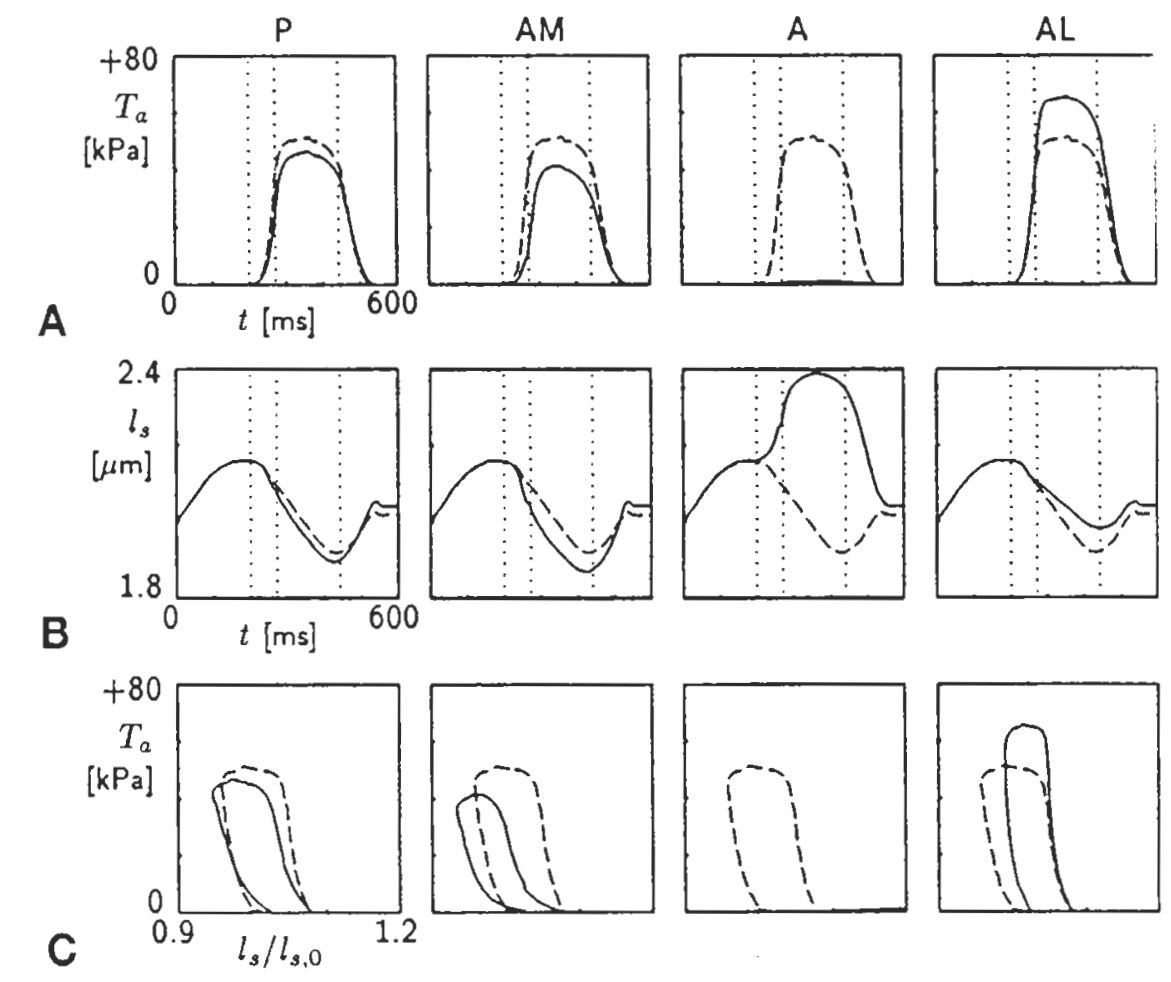

Changes in the distribution of active stress in case of ischemia, as represented by the normalized active stress $\hat{\mathrm{T}}_{\mathrm{a}}(E q .7)$, are shown in Fig. $7 B$. At the epicardium, a region of low stress was found, corresponding to the ischemic region. This low-stress region extended beyond the ischemic region along the fibers in the medial-basal direction. Regions of elevated stress were observed halfway between equator and apex, at the medial and lateral margins. At the endocardium, a less-pronounced but similar pattern was found: the low-stress region again extended along the fibers.

Figure $7 C$ shows the redistribution of sarcomere shortening during ejection due to ischemia, as represented by the normalized sarcomere shortening $J \hat{l}_{\text {s.e }}$ (Eq. 9). Within the ischemic region, sarcomeres length- ened as much as they normally shortened $\left(\Delta \hat{l}_{\mathrm{s}, \mathrm{e}} \approx-1\right)$. When epicardial locations are compared at the same latitude, fiber shortening was larger at the medialbasal side of the ischemic region than at the lateralbasal side. At the endocardium, a similar pattern is found, but now fiber shortening is relatively large on the lateral-basal side. In the major part of the ventricle, sarcomere shortening was approximately normal $\left(\unlhd \hat{l}_{s, e} \approx 1\right)$.

In Fig. $7 D$, the redistribution of external work due to ischemia, as represented by $\hat{w}(E q .11)$, is shown. $\hat{w}$ was $<1$ almost everywhere. At the epicardial and the endocardial wall, the region of reduced work extended beyond the ischemic region, especially along the local fiber direction.
A

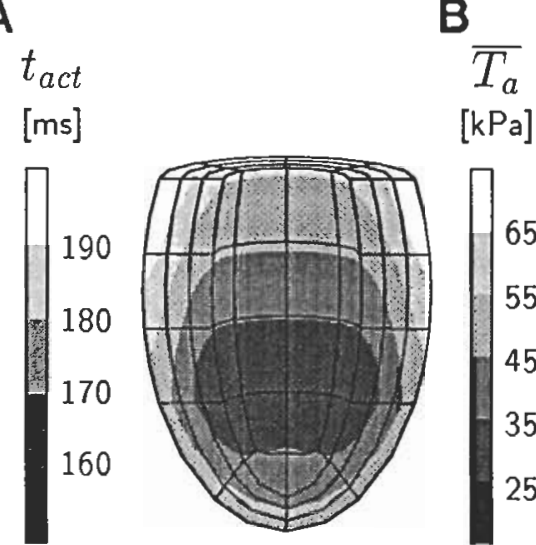

C

$\Delta l_{s, e}$

$[\mu \mathrm{m}]$

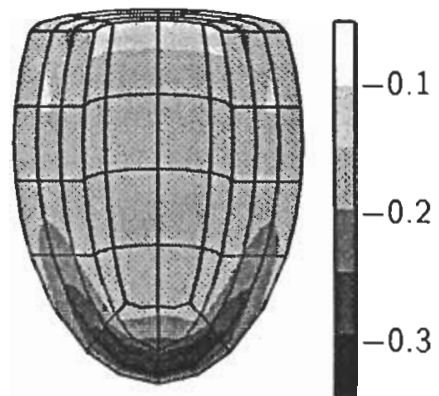

D $w$ $[\mathrm{mJ} / \mathrm{ml}]$

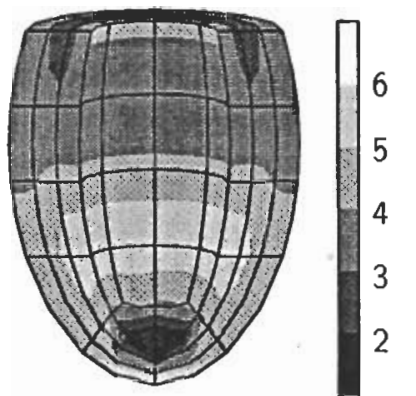

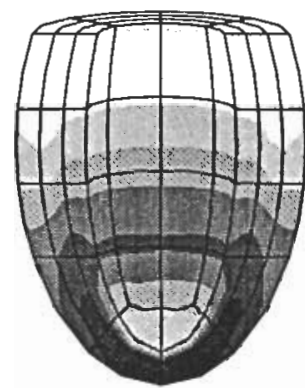

Fig. 6. Local mechanics in an arbitrary half of normal ventricle, $A$ : activation sequence of ventricular wall. $B$ : distribution of mean active fiber stress during ejection $\left(\overline{\mathrm{T}}_{\mathrm{a}} ; E q .6\right) . C$ : distribution of sarcomere shortening during ejection $\left(\Delta \iota_{s, e} ; E q .8\right)$. D: distribution of external work $(w ; E q .10)$. 


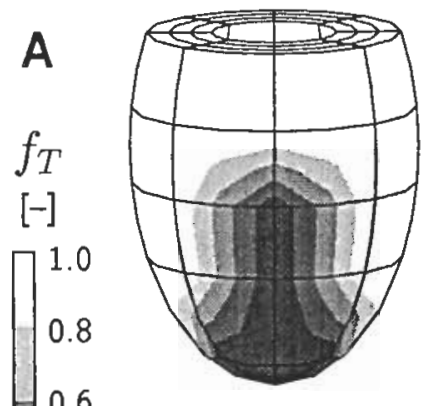

0.6
0.4
0.2
0.0

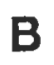

B

$\widehat{T}_{a}$ $[-]$

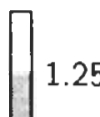

1.00

L

0.75

0.75

0.50
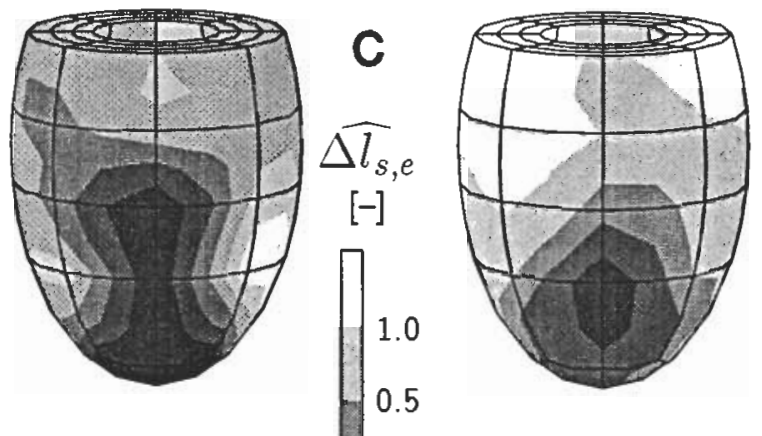

D

$\widehat{w}$

$[-]$

0.25

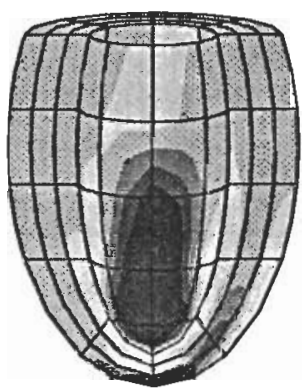

0.0

$-0.5$

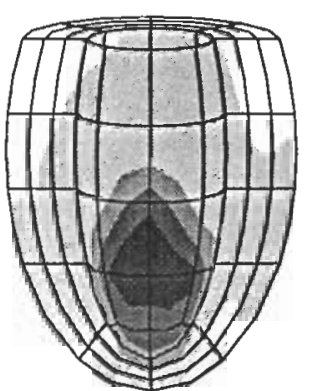

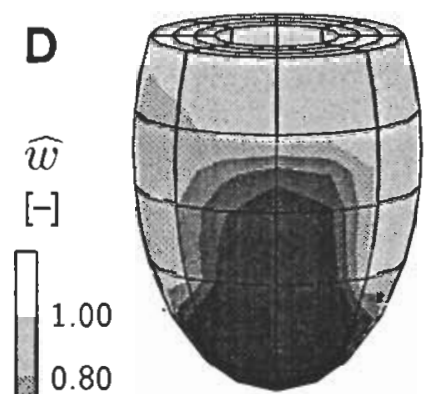

0.60

0.40

0.20

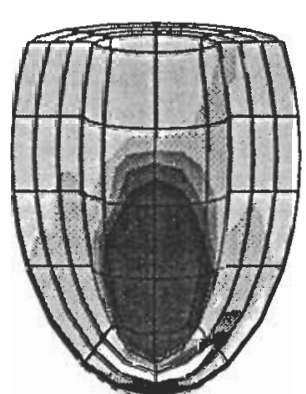

Fig. 7. Local mechanics in anterior half of ischemic ventricle at epicardium (top) and endocardium (bottom : mediai (. $h$ ) and lateral $(L)$ sides are indicated. $A$ : location of ischemic region. $B$ : distribution of normalized active stress $\left(T_{:}:\right.$ $E q .7)$. C: distribution of normalized sarcomere shortening $\left(\lambda_{*}: E q .91 . D\right.$ : distribution of normalized work $l i C$ : Eq. 11).

For comparison with the experimental results, in Fig. 8A, epicardial fiber strain during ejection ( $E q .12)$ is plotted vs. volume strain ( $E q$. 13). The slope of the best linear fit between fiber and volume strain represents $a(E q .15)$. The spatial distribution of the strain ratio (Fig. 9) varies from $>0.4$ in the nonischemic region $\left(f_{\mathrm{T}} \approx 1\right)$ to $<0$ in the ischemic region $\left(f_{\mathrm{T}}<0.2\right)$. The latter negative values of $a$ correspond to fiber stretch during ejection, which is associated with bulging of the ventricular wall.

\section{Experimental Results}

In Fig. $8 B$, the change in epicardial fiber strain with volume strain during ejection, as measured in experiment 1, is shown. In Fig. 9, $\hat{\mathrm{q}}$ and $\alpha$ are shown for all four experiments. Within the video-marker region. the location of the ischemic region, associated with the region of low $\hat{q}$, varied from experiment to experiment. In experiments 2 and 3 , a large fraction of the observed region was ischemic, whereas in experiments 1 and 4
A

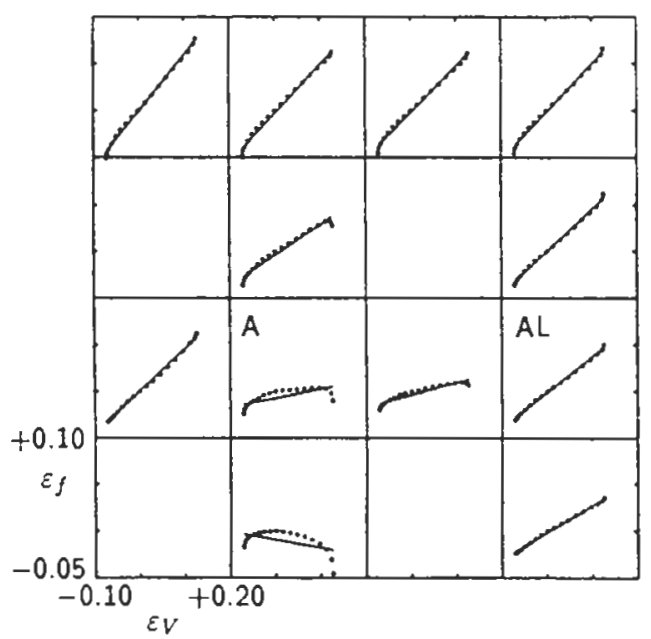

B

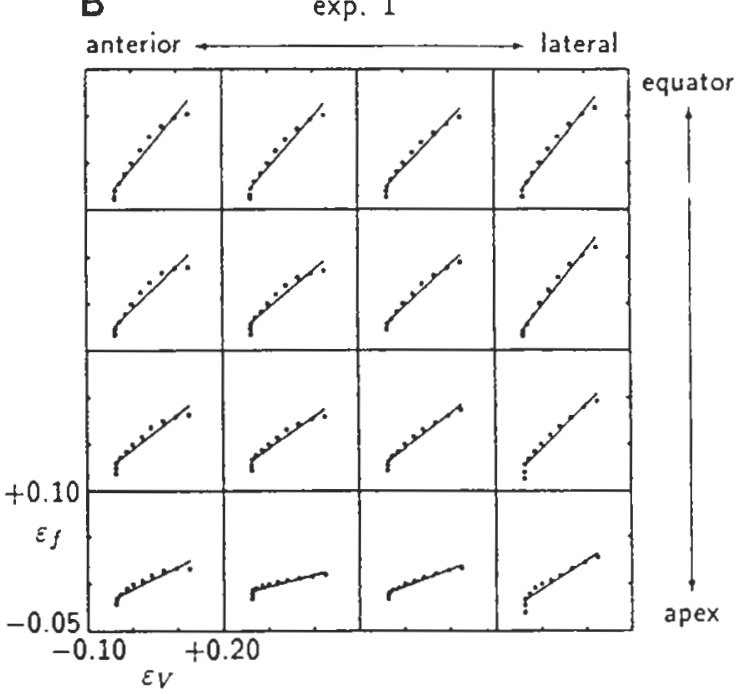

Fig. 8. Epicardial fiber strain ( $\epsilon_{f}: E q .12$ ) plotted vs. volume strain $\left(\epsilon_{\mathrm{v}}: E q .13\right.$; $)$. Slope of best linear fit between $\epsilon_{\mathrm{f}}$ and $\epsilon_{\mathrm{v}}$, indicated by solid line, represents fiber-to-volume strain ratio $(\alpha ; E q .14)$. A: results from model simulation for 12 nodes (see Fig. $1 G$ for nodes $A$ and $A L$ ). B: results from experiment 1 for 16 subregions, as indicated in Fig. 2. 


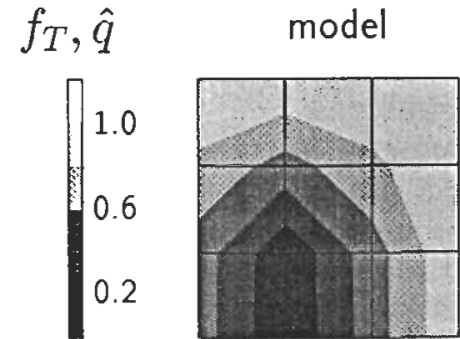

exp. 1

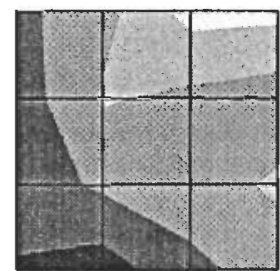

exp. 2

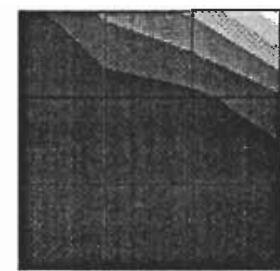

exp. 3
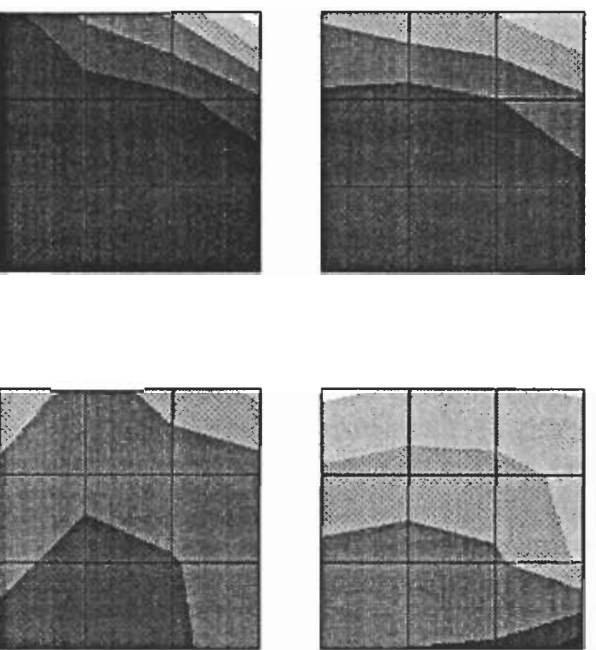

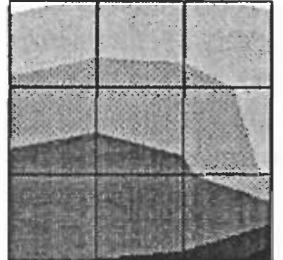

exp. 4
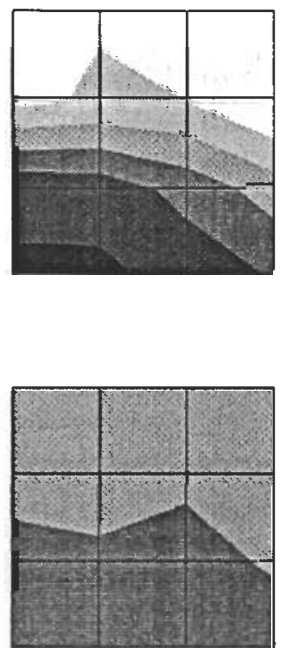

Fig. 9. Top: epicardial distributions of factor $f_{\mathrm{T}}(E q .3)$ representing fraction of normal isometric stress that can be generated (in model) and of normalized myocardial perfusion $\hat{\mathrm{q}}$ ( $E$ (q. 16; in expts 1-4). Bottom: epicardial distributions of $a: 3 \times 3$ regions correspond to central $3 \times 3$ regions in Fig. $2 B$.

the major part was relatively well perfused. $\alpha$ varied from about -0.2 in the ischemic region to 0.6 in the nonischemic region. The latter value compares quite well with that in the nonischemic ventricle, which was $0.69=0.09,0.69 \pm 0.25,0.77 \pm 0.12$, and $0.63 \pm 0.04$ (mean $\pm \mathrm{SD}$ over 16 regions) in experiments 1,2,3, and 4 , respectively.

\section{DISCUSSION}

\section{Model}

Many aspects of ventricular mechanics are incorporated in the present model: the thick-walled geometry, the varying muscle fiber orientation across the wall, the anisotropy of the passive myocardial tissue, and the dependency of active stress on time, strain, and strain rate. Naturally, not all physiological aspects were taken fully into account. For example, model simplifications concerning geometry and material properties were introduced.

Modeling of a realistic nonsymmetric geometry is possible, because the calculation setup is threedimensional. However, because of the lack of detailed experimental geometrical data, we chose an axisymmetric model for the normal ventricle. Thus, because geometrical and material properties do not vary in the circumferential direction, the calculated local mechanics for the normal ventricle are axisymmetric also. As a convenient consequence, deviations from axisymmetry, as found in the case of ischemia, can be completely attributed to the presence of the ischemic region.

In the model, we neglected viscous properties of the passive tissue, relative motion of the fluid with respect to the solid, and residual stresses and strains. This simplification is motivated by the fact that the stresses associated with these properties are typically around 1 $\mathrm{kPa}$, which is small compared with the active fiber stresses during systole (on the order of $50 \mathrm{kPa}$ ) (6).
Ischemia is modeled by disabling the generation of active stress while leaving all other properties, such as passive material behavior and activation sequence, unchanged. Thus the present results reflect best the mechanics in the ventricle immediately after the occurrence of ischemia.

Because we focus primarily on left ventricular mechanics during ejection, we did not simulate in detail the diastolic phase, including mitral valve mechanics. Instead, during diastole, the change in ventricular pressure was prescribed in time. Ventricular afterload was represented by a three-element model, without regard for inertial effects of the blood in the outflow tract. We believe that the limitations in the modeling of preload and afterload do not restrict our conclusions with respect to regional ventricular mechanics during ejection; the distributions of wall stress and strain during the latter phase were virtually independent of the preload (see simulation VAR2 below) and afterload (5) conditions, because changes in hemodynamic loading affect all regions in the wall simultaneously and equally.

The numerical model involves discretization in time and space. We used a 5-ms time step, except for the periods around the switching between phases in the cycle, where 2-ms time steps were applied. Lowering the time steps from 5 to $2 \mathrm{~ms}$ in the entire simulation did not change the solution. The spatial discretization into 108 elements is rather coarse, but in view of the large computation times, it was impractical to perform mesh refinement. Consequently, the spatial resolution of calculated changes in fiber stress, strain, and work is limited; we cannot accurately quantify the regional extent of the effects of ischemia.

\section{Results From the Simulations}

The mechanics of the normal ventricle, as calculated by the present model, have been discussed previously 
$(6,7)$. The calculated rotation of the wall around the ventricular long axis, showing transmural differences in angle of rotation up to $40^{\circ}$, does not seem realistic; lack of suitable experimental data prevents a detailed quantitative comparison of numerical and experimental results in this respect (see discussion in Ref. 7). A more realistic rotational behavior may be obtained by introducing a transverse component in the muscle fiber path, thus accounting for the endo-epicardial crossover of the muscle fibers (7). Previously, local wall mechanics were found to be strongly dependent on the choice of the transmural variation in muscle fiber orientation (6, 7 ). In this study, the transmural variation was chosen so that active fiber stress is distributed homogeneously across the ventricular wall (Fig. 6) (6). Despite this homogeneity in stress, generated mechanical work is distributed rather inhomogeneously across the wall because of spatial differences in the moment of activation. In early-activated regions, sarcomeres shorten already during the isovolumic contraction phase, thereby stretching the sarcomeres in late-activated regions (7). Consequently, at the beginning of the ejection phase, the early-activated fibers are relatively short and unable to shorten substantially further, whereas the late-activated fibers are able to shorten strongly from a relatively large initial length at the beginning of ejection. In the real ventricle, similar effects have been found, but only under abnormal conditions of electrical activation, occurring, for example, during ventricular pacing $(9,21)$. Apparently, our model needs closer inspection in this respect.

In the ischemic ventricle, an ischemic region comprising $\sim 12 \%$ of the ventricular wall reduced stroke work by $\sim 25 \%$. Thus only part of the loss of pump work may be attributed to the missing contribution of the ischemic region. The other part may be attributed to decreased efficiency of the nonischemic tissue, caused by 1) a conversion of generated work, normally contributing to stroke work, into elastic energy stored in the bulging ischemic region and 2) a reduced capability of the muscle cells in the border zone, i.e., the region with nonischemic tissue adjacent to the ischemic region, to generate external work. The reduced capability is caused by a reduction in active stress or sarcomere shortening (Figs. 5 and 6). A reduced active stress level is found in the "serial" border zone, i.e., that part of the border zone where fibers are in series with the fibers in the ischemic region. These fibers, experiencing a relatively low load by the ischemic region, can shorten relatively easily at a low stress level. Because the decreased stress is not fully compensated for by an increased fiber shortening, generated external work is less than normal. In the "parallel" border zone, i.e., that part of the border zone where fibers are parallel to those in the ischemic region, fibers take over part of the load transmission through the ischemic region. Thus stress in these fibers is relatively high. Nevertheless generated external work is less than normal because of reduced fiber shortening due to mechanical coupling of these fibers to the stretching fibers in the ischemic region. The existence of a serial and a parallel border zone is clearly found at the epicardial surface. At the endocardial surface, the same phenomena are found, although they are less prominent.

In the model, the sarcomeres in the ischemic region may be stretched to $>2.5 \mu \mathrm{m}$. However, in papillary muscle experiments, maximum sarcomere length was $\sim 2.4 \mu \mathrm{m}$ (25). Thus, in the model, the stiffness of the passive tissue at large deformations is underestimated. A larger stiffness is expected to reduce the differences in mechanical load in the border zone: in the serial border zone, fiber stress will increase and fiber shortening will decrease because of the enhanced loading by the stiffer tissue in the ischemic region, whereas in the parallel border zone, fiber stress will decrease and fiber shortening will increase because of the enhanced load transmission through the ischemic region. Thus stroke work may be higher because of the reduced deformation of the ischemic region and the increased ability to generate external work in the border zone. The same arguments apply to the in vivo situation, where the ischemic region stiffens during the first days after the occurrence of ischemia. Because of this stiffening, an improvement in pumping performance may be expected.

The typical deformation of the septal half of the ventricle, showing a bulging of the ischemic region, has also been found in experiments (1). Because of the dependence of local mechanics on muscle fiber orientation, the deformation of the anterior wall is asymmetric (Fig. 4), despite the symmetric location of the ischemic region with respect to the anterior-posterior plane. Thus estimation of the size and location of the ischemic region from the deformation pattern of the ventricle, as, for example, assessed with ultrasound techniques, is not straightforward: a region of abnormal wall motion may not be identified as a region of ischemia.

\section{Results of Some Parameter Variations}

To investigate whether the specific dependency of changes in local wall mechanics on fiber orientation varies with the transmural distribution of ischemia and afterload, two additional simulations were performed. In both simulations, the size of the ischemic region was kept unchanged.

In simulation VAR1, the degree of ischemia decreased from $100 \%$ at the endocardium to $0 \%$ at the epicardium. As a result, stroke volume was reduced by $\sim 8 \%$ (Fig. 10), which is one-half of the reduction in the case of complete transmural ischemia. At the endocardial surface, the distribution of normalized active fiber stress (Fig. 11) was virtually identical to that of a complete transmural ischemia. At the epicardial surface, stress in the serial border zone was only slightly reduced. Apparently, changes in fiber stress due to ischemia are confined to the layer in which the ischemic region is located. This finding held also for changes in sarcomere shortening during ejection and work (results 


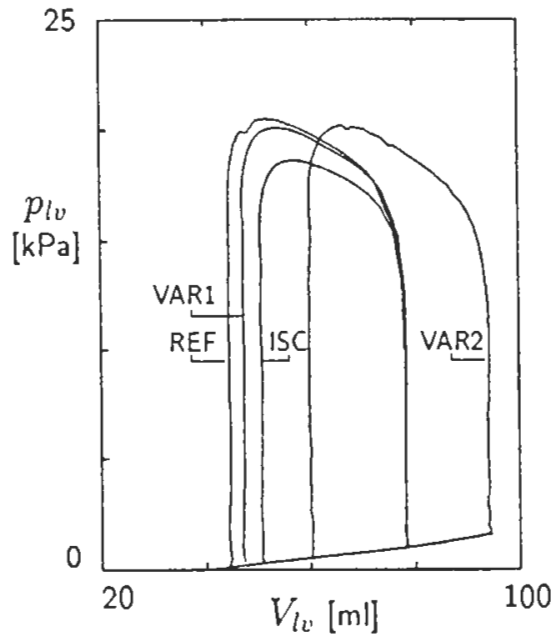

Fig. 10. Pressure-volume loops, as calculated in simulations for normal ventricle $\mathrm{REF}$, and ischemic ventricle with $100 \%$ transmural ischemia (ISC), subendocardial ischemia (VAR1), and 100'; transmural ischemia with increased preload (VAR2).

not shown). This could change if the transmural crossover of the fibers was taken into account, because this crossover increases the mechanical interaction between the layers $(7)$.

In simulation VAR2, end-diastolic filling pressure was elevated to $1.6 \mathrm{kPa}$. As a result, end-diastolic volume increased by $21 \%$, while stroke volume was restored to its original value (Fig. 10). Normalized active fiber stress during ejection increased slightly. but its spatial distribution remained virtually unchanged (Fig. 11). The spatial distributions of sarcomere shortening during ejection and work were also not affected (results not shown). Thus the change in preload affects all regions in the wall simultaneously and equally.

In conclusion, the finding, in the original simulation with a complete transmural ischemia, that fiber stress is relatively low in the serial border zone and high in the parallel border zone holds also for simulations VAR 1 and VAR2.

In view of the large computation times, it is impractical to perform a detailed sensitivity analysis. However, on the basis of simulations of the mechanics of the normal ventricle, we concluded that a qualitative change in the distribution of wall stress and strain may be expected only if the spatial distribution of the model parameters is changed. Such changes may concern the spatial distribution of the muscle fiber orientation $(6$, 7 ), the moment of activation (5), or the ability to generate active stress (this study). Changes in model parameters that affect all regions in the ventricular wall equally, such as changes in preload or afterload, or a change in muscle mechanics parameters that is identical for all parts in the wall will affect local mechanics only quantitatively, without affecting the spatial distribution across the ventricular wall (5).

We have presented normalized quantities, as defined in Eqs. 7, 9, and 11. Thus even changes that do affect the spatial distribution of local wall mechanics might have no significant qualitative influence on the present results, because those changes might affect mechanics in the normal and ischemic ventricle similarly. In conclusion, we expect that only regional changes in muscle mechanics parameters in the ischemic ventricle
VAR1
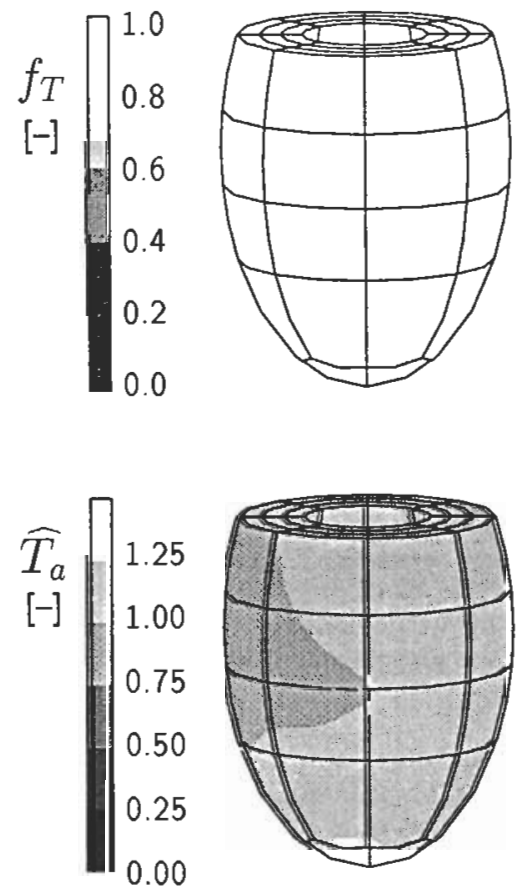
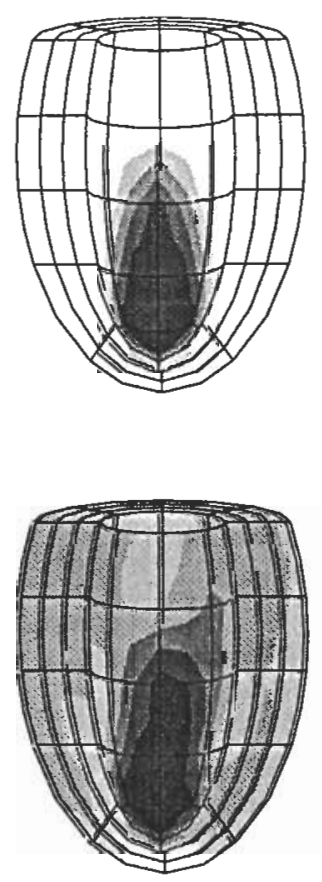
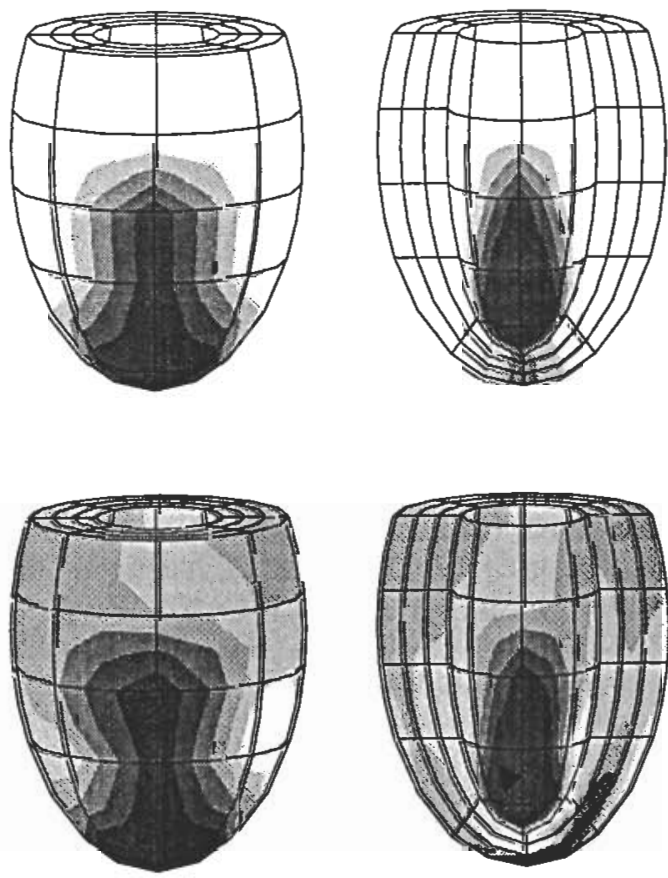

Fig. 11. Distributions of ischemia in terms of $f_{\mathrm{T}}(E q .3)$ and $\hat{\mathrm{T}}_{\mathrm{a}}(E q .7)$ in case of subendocardial ischemia (VAR1) and $100 \%$ transmural ischemia with increased preload (VAR2). 
with respect to the normal ventricle may have considerable influence on the present results.

\section{Comparison of Simulated and Experimental Results}

Figure 9 shows that it was difficult to predict the location of the ischemic region on the basis of the coronary arteries visible at the epicardial surface; although we tried to locate the video-marker region so that about one-half of it became ischemic, the location of the ischemic region, associated with the region of low $\hat{\mathrm{q}}$, varied from experiment to experiment. In the experiment, $\epsilon_{\mathrm{f}}$ and $\epsilon_{\mathrm{V}}$ were related approximately linearly during ejection (Fig. 8). In the normal ventricles, $a$ of $\sim 0.7$ was found, meaning that, for a regular stroke volume of $25 \%$ of wall volume, the decrease in epicardial fiber length during ejection is $\sim 17 \%(E q .13)$. In the ischemic ventricle, the strain ratio ranged from $\sim 0.6$ in the nonischemic region $(\hat{\mathrm{q}} \approx 1)$ to less than -0.2 in the ischemic region $(\hat{\mathrm{q}}<0.4)$.

In the simulations, a linear relation between $\epsilon_{\mathrm{f}}$ and $\epsilon_{\mathrm{V}}$ during ejection was also found. In the normal ventricle, $a$ for the epicardial region, corresponding to the experimental site, was calculated to be $0.39 \pm 0.04$, which is smaller than the experimental value. In the ischemic ventricle, the trend was similar to that in the experiments: $a$ ranged from $\sim 0.4$ in the nonischemic region $\left(f_{\mathrm{T}} \approx 1\right)$ to $<0$ in the ischemic region $\left(f_{\mathrm{T}}<0.2\right)$.

The simulation predicts an asymmetric spatial distribution of $\epsilon_{\mathrm{f}}$ with respect to the ischemic region (Fig. $5 B$ ). Unfortunately, validation of this asymmetry from our experiments was impossible, because only the lateral side of the ischemic region was accessible, whereas the septal side was hidden by the right ventricle. Possibly, the asymmetry may be found by occlusion of a descending branch of the circumflex artery. We are not aware of any such experiments presented in literature. Moreover this effect may be obscured in the real ventricle because of the deviation from axisymmetry.

\section{Comparison With Models Presented in Literature}

In our model, a $12 \%$ reduction in the volume of normally contracting tissue resulted in an $18 \%$ decrease in stroke volume. This finding agrees very well with the results obtained in the membrane model presented by Bogen et al. (4), in which the fractional decrease in stroke volume was $\sim 1.5$ times the fractional decrease in the amount of normally contracting tissue. In the finite-element model presented by Perl and Horowitz (16), the fractional decrease in stroke volume was only $\sim 0.75$ times the fractional decrease of normally contracting tissue. Bogen et al. conclude that in case of "immediate infarction," i.e., the case where contractile function is completely lost but passive material properties are unaltered, the deleterious effect of the infarct must be attributed to transfer of blood volume into the bulging infarcted region and to a reduced mechanical function in the myocardial border zone. In their model, the reduction of mechanical function in the border zone was due to "constrained motion" of the border zone, and stresses in the border zone were predicted to be about four times greater than those far away from the infarct. We support these conclusions, but we do not agree with the explanation for the reduced mechanical function in the border zone in general. Instead, we find that the mechanism by which mechanical function is reduced is different in the serial and parallel border zone.

\section{Conclusions}

From the model simulations, we conclude that 1) an ischemic region comprising $\sim 12 \%$ of the left ventricular wall mass yields an $\sim 18 \%$ reduction in stroke volume and an $\sim 25 \%$ reduction in stroke work, 2 ) in the serial border zone, i.e., the part of the border zone where fibers are in series with the fibers in the ischemic region, generated mechanical work is reduced because of a reduced systolic fiber stress that is not fully compensated for by an increased systolic fiber shortening, 3) in the parallel border zone, i.e., the part of the border zone where fibers are parallel to the fibers in the ischemic region, generated mechanical work is reduced because of a reduced systolic fiber shortening that is not fully compensated for by an increased systolic fiber stress, and 4) because of the anisotropy of the myocardial tissue, the global deformation pattern of the ventricle is asymmetric with respect to the ischemic region. From the comparison of results from simulations and experiments, we conclude that 1 ) in the experiment and in the model, during ejection, epicardial fiber strain is related approximately linearly to volume strain; the slope of this linear relation is similar in experiment and model, ranging from $\sim 0.5$ in the nonischemic region to $<0.0$ in the ischemic region, and 2 ) the existence of a serial and a parallel border zone, as predicted by the model, cannot be verified from our experiments, because the septal side of the ischemic region is obscured by the right ventricle. Because to our knowledge no experiments supporting or contradicting these border zone characteristics have been presented in the literature, the model results might initiate such experiments. With respect to the setup of the model, we conclude that 1) the lack of detailed input data on geometry, fiber structure, and (spatial variation of) material properties poses a major problem, and 2) although a fair computing power has been used, this power is too small to allow us to perform a detailed sensitivity analysis in a sufficiently fine finite-element mesh.

This work was supported by Netherlands Organization for Scientific Research Grant 900-536-024.

Address for reprint requests: P. H. M. Bovendeerd, Dept. of Mechanical Engineering, Eindhoven University of Technology, PO Box 513, $5600 \mathrm{MB}$ Eindhoven, The Netherlands.

Received 9 September 1993; accepted in final form 6 June 1995

\section{REFERENCES}

1. Akaishi, M., W. S. Weintraub, R. M. Schneider, L. W. Klein, J. B. Agarwal, and R. H. Helfan. Analysis of systolic bulging: mechanical characteristics of acutely ischemic myocardium in the conscious dog. Circ. Res. 58: 209-217, 1986.

2. Arts, T., P. C. Veenstra, and R. S. Reneman. Epicardial deformation and left ventricular wall mechanics during ejection 
in the dog. Am. J. Physiol. 243 (Heart Circ. Physiol. 12): H379-H390, 1982.

3. Beyar, R., and S. Sideman. A computer study of the left ventricular performance based on fiber structure, sarcomere dynamics, and transmural electrical propagation velocity. Circ. Res. 55: 358-375, 1984.

4. Bogen, D. K., S. A. Rabinowitz, A. Needleman, T. A. McMahon, and W. H. Abelmann. An analysis of the mechanical disadvantage of myocardial infarction in the canine left ventricle. Circ. Res. 47: 728-741, 1980.

5. Bovendeerd, P. H. M. The Mechanics of the Normal and Ischemic Left Ventricle During the Cardiac Cycle: A Numerical and Experimental Analysis ( $\mathrm{PhD}$ thesis). Maastricht, The Netherlands: University of Limburg, 1990.

6. Bovendeerd, P. H. M., T. Arts, J. M. Huyghe, D. H. van Campen, and R.S. Reneman. Dependence of local left ventricular wall mechanics on myocardial fiber orientation: a model study. J. Biomech. 25: 1129-1140, 1992.

7. Bovendeerd, P. H. M., J. M. Huyghe, T. Arts, D. H. van Campen, and R. S. Reneman. Influence of endo-epicardial crossover of muscle fibers on left ventricular wall mechanics. $J$. Biomech. 27: 941-951, 1994.

8. Delhaas, T., T. Arts, P. H. M. Bovendeerd, F. W. Prinzen, and R. S. Reneman. Subepicardial fiber strain and stress as related to left ventricular pressure and volume. Am. J. Physiol. 264 (Heart Circ. Physiol. 33): H1548-1559, 1993.

9. Delhaas, T., T. Arts, F. W. Prinzen, and R. S. Reneman. Relation between regional electrical activation time and subepicardial fiber strain in the canine left ventricle. Pfluegers Arch. 423: 78-87, 1993.

10. Hill, A. V. The heat of shortening and the dynamic constants in muscle. Proc. R. Soc. Lond. 126: 136-165, 1938

11. Huisman, R. M., G. Elzinga, and N. Westerhof. Measurement of left ventricular wall stress. Cardiovasc. Res. 14: 142-153, 1980.

12. Huisınan, R. M., P. Sipkema, N. Westerhof, and G. Elzinga. Comparison of models used to calculate left ventricular wall force. Med. Biol. Eng. Comput. 18: 133-144, 1980.

13. Huyghe, J. M., T. Arts, D. H. van Campen, and R. S. Reneman. Porous medium finite element model of the beating left ventricle. Am. J. Physiol. 262 (Heart Circ. Physiol. 31): H $1256-\mathrm{H} 1267,1992$.

14. Muijtjens, A. A. M., J. M. A. Roos, T. T. Prinzen, A. Hasman, R. S. Reneman, and T. Arts. Noise reduction in estimating cardiac deformation from marker tracks. Am. J. Physiol. 258 (Heart Circ. Physiol. 27): H599-H605, 1990.

15. Nikolić, S., E. L. Yellin, K. Tamura, H. Vetter, T. Tamura, J. S. Meisner, and R. W. M. Frater. Passive properties of canine left ventricle: diastolic stiffness and restoring forces. Circ. Res. 62: $1210-1222,1988$

16. Perl, M., and A. Horowitz. Mechanical model for the simulation of ischaemia and infarction of the left ventricle. Med. Biol. Eng. Comput. 25: 284-288, 1987.
17 Perl, M., A. Horowitz, and S. Sideman. Comprehensive model for the description of left ventricle mechanics. 1. Model descrip tion and simulation procedure. Med. Biol. Eng. Comput. 24: $145-149,1986$

18. Peskin, C. S., and D. M. McQueen. A three-dimensional computational method for blood flow in the heart. I. Immersed elastic fibers in a viscous incompressible fluid. J. Comput. Physics 81: 372-405, 1989.

19. Prinzen, T. T., T. Arts, F. W. Prinzen, and R. S. Reneman. Mapping of epicardial deformation using a video processing technique. J. Biomech. 19: 263-273, 1986.

20. Prinzen, F. W., T. Arts, G. J. van der Vusse, W. A. Coumans, and R. S. Reneman. Gradients in fiber shortening and metabolism across the ischemic left ventricular wall. Am. J. Physiol. 250 (Heart Circ. Physiol. 19): H255-H264, 1986.

21. Prinzen, F. W., C. H. Augustijn, T. Arts, M. A. Allessie, and R. S. Reneman. Redistribution of myocardial fiber strain and blood flow by asynchronous activation. Am. J. Physiol. 259 (Heart Circ. Physiol. 28): H300-H308, 1990.

22. Streeter, D. D. Gross morphology and fiber geometry of the heart. In: Handbook of Physiology. The Cardiovascular System. The Heart, Bethesda, MD: Am. Physiol. Soc., 1979, sect. 2, vol. I, chapt. 4, p. 61-112.

23. Streeter, D. D., and W. T. Hanna. Engineering mechanics for successive states in canine left ventricular myocardium. Circ. Res. 33: 639-655, 1973.

24. Streeter, D. D., H. M. Spotnitz, D. P. Patel, J. R. Ross Jr., and $\mathrm{E}$. H. Sonnenblick. Fiber orientation in the canine left ventricle during diastole and systole. Circ. Res. 24: 339-347, 1969.

25. Ter Keurs, H. E. D. J., W. H. Rijnsburger, R. van Heuningen, and M. J. Nagelsmit. Tension development and sarcomere length in rat cardiac trabeculae: evidence of length-dependent activation. Circ. Res. 46: 703-714, 1980

26. Van der Vusse, G. J., T. Arts, J. F, C. Glatz, and R. S. Reneman. Transmural differences in energy metabolism of the left ventricular myocardium: fact or fiction. J. Mol. Cell. Cardiol. 22: 23-37, 1990 .

27. Waldman, L. K., Y. C. Fung, and J. W. Covell. Transmural myocardial deformation in the canine left ventricle: normal in vivo three-dimensional finite strains. Circ. Res. 57: 152-163, 1985.

28. Westerhof, N., G. Elzinga, and G. C. van den Bos. Influence of central and peripherical changes on the hydraulic input impedance of the systemic arterial tree. Med. Biol. Eng. 11: $710-723,1973$

29. Yin, F. C. P. Applications of the finite-element method to ventricular mechanics. CRC Crit. Rev. Biomed. Eng. 12: 311$342,1985$.

30. Yin, F. C. P., R. K. Strumpf, P. H. Chew, and S. L. Zeger. Quantification of the mechanical properties of noncontracting canine myocardium under simultaneous biaxial loading. J. Biomech. 20: 577-589, 1987. 